January 2016

\title{
Engaging Diverse Students in Statistical Inquiry: A Comparison of Learning Experiences and Outcomes of Under-Represented and Non-Underrepresented Students Enrolled in a Multidisciplinary Project-Based Statistics Course
}

\author{
Lisa Dierker (AE) \\ Wesleyan University, Idierker@wesleyan.edu \\ Jalen Alexander \\ Jennifer L. Cooper \\ Arielle Selya \\ Jennifer Rose
}

See next page for additional authors

Follow this and additional works at: https://digitalcommons.georgiasouthern.edu/ij-sotl

\section{Recommended Citation}

Dierker (AE), Lisa; Alexander, Jalen; Cooper, Jennifer L.; Selya, Arielle; Rose, Jennifer; and Dasgupta, Nilanjana (2016) "Engaging Diverse Students in Statistical Inquiry: A Comparison of Learning Experiences and Outcomes of Under-Represented and Non-Underrepresented Students Enrolled in a Multidisciplinary Project-Based Statistics Course," International Journal for the Scholarship of Teaching and Learning: Vol. 10: No. 1, Article 2.

Available at: https://doi.org/10.20429/ijsotl.2016.100102 


\title{
Engaging Diverse Students in Statistical Inquiry: A Comparison of Learning Experiences and Outcomes of Under-Represented and Non-Underrepresented Students Enrolled in a Multidisciplinary Project-Based Statistics Course
}

\begin{abstract}
Introductory statistics needs innovative, evidence-based teaching practices that support and engage diverse students. To evaluate the success of a multidisciplinary, project-based course, we compared experiences of under-represented (URM) and non-underrepresented students in 4 years of the course. While URM students considered the material more difficult than non-URM students, URM students demonstrated similar levels of increased confidence in applied skills and interest in follow up courses as non-URM students. URM students were found to be twice as likely as non-URM students to report that their interest in conducting research increased. Increasing student confidence and interest gives all students a welcoming place at the table that will afford the best hope for achieving the kind of statistical literacy necessary for interdisciplinary research.

\section{Keywords}

statistics, multidiscplinary, project-based, higher education

\section{Creative Commons License}

(c) $($ ) $\odot$

This work is licensed under a Creative Commons Attribution-Noncommercial-No Derivative Works 4.0 License.

\section{Cover Page Footnote}

This research was supported by grant 0942246 and 1323084 from the National Science Foundation, Transforming Undergraduate Education in Science, Technology, Engineering and Mathematics (TUES) and the Lauren B. Dachs Grant in Support of Interdisciplinary Research in the Social Impacts of Science. We appreciate the generous efforts of our colleagues and advisors who contributed to the development and implementation of this course.
\end{abstract}

Authors

Lisa Dierker (AE), Jalen Alexander, Jennifer L. Cooper, Arielle Selya, Jennifer Rose, and Nilanjana Dasgupta 


\title{
Engaging Diverse Students in Statistical Inquiry: A Comparison of Learning Experiences and Outcomes of Under-Represented and Non-Underrepresented Students Enrolled in a Multidisciplinary Project-Based Statistics Course
}

\author{
Lisa Dierker', Jalen Alexander', Jennifer L. Cooper', Arielle Selya ${ }^{2}$, Jennifer Rose', Nilanjana Dasgupta ${ }^{3}$ \\ 'Psychology Department, Wesleyan University, Middletown, CT 06459, USA \\ ${ }^{2}$ Department of Population Health, University of North Dakota, Grand Forks, ND 58202, USA \\ ${ }^{3}$ Department of Psychological and Brain Sciences, University of Massachusetts, Amherst, MA 01003, USA
}

(Received 19 Aug 2015; accepted 17 Dec 2015)

\begin{abstract}
Introductory statistics needs innovative, evidence-based teaching practices that support and engage diverse students. To evaluate the success of a multidisciplinary, project-based course, we compared experiences of under-represented (URM) and non-underrepresented students in 4 years of the course. While URM students considered the material more difficult than non-URM students, URM students demonstrated similar levels of increased confidence in applied skills and interest in follow up courses as non-URM students. URM students were found to be twice as likely as non-URM students to report that their interest in conducting research increased. Increasing student confidence and interest gives all students a welcoming place at the table that will afford the best hope for achieving the kind of statistical literacy necessary for interdisciplinary research.
\end{abstract}

\section{INTRODUCTION}

A central challenge of introductory statistics is the development of a curriculum that not only serves diverse students, but also sparks communication, reasoning and collaboration that clearly crosses traditional disciplinary boundaries. Previous authors have suggested that this can best be achieved through inquiry-based projects (Bailey, Spence, \& Sinn 2013) that allow students to "decompose their topic, identify key components; abstract and formulate different strategies for addressing it; connect the original question to the statistical framework; choose and apply methods; reconcile the limitations of the solution; and communicate findings" (Nolan \& Temple Lang, 2009). This type of project-based learning is most commonly defined as an instructional approach based on authentic, real-world activities that are aimed at engaging student interest and enthusiasm (BIE, 2012; Krajcik \& Blumenfeld, 2006). Designed to answer a question or solve a problem, this approach allows students to face challenges that lead to answers, reflect on ideas and make decisions that affect project outcomes (Aditomo, Goodyear, Bliuc, \& Ellis, 2013). There is an emerging literature showing that project-based learning in many contexts is more effective in promoting deep thinking, the ability to apply knowledge, communication and reasoning skills, when compared to traditional didactic approaches (e.g. Harada \& Yoshina, 2004; Hickey, Wolfe, \& Kindfield, 2000; Hickey, Kindfield, Horwitz, \& Christie, 1999; Hmelo-Silver, Duncan, \& Chinn, 2007; Langer, 200 I; Lynch, Kuiper, Pyke, \& Szesze, 2005; Walker \& Leary, 2009; however, see Kirschner, Sweller, \& Clark, 2006).

Though accumulating research has shown that project-based activities, especially those providing a research experience (Russell, Hancock, \& McCullough, 2007), promote positive learning outcomes and may hold promise for better engaging students with varying levels of preparation (Hatfull et al., 2006; Jones, Rasmussen, \& Moffitt, 1997; Mergendoller, Maxwell, \& Bellisimo, 2006), little research has focused on group differences that may predict greater or lesser success for project-based learners. Consideration of group differences is particularly important in courses within STEM fields where retention of underrepresented minority students (URM) has been weak with URM students being less likely to persist in STEM fields at all levels (e.g., HERI, 20I0; Schultz et al., 20I I; daSilva and
Pinto, 20I4; Bilgin, et al, 20I5). In fact, underrepresented students often exit science and mathematics following introductory courses (National Science Foundation - Division of Science Resources Statistics, 2004) and of the numerous reasons indicated for this early departure, the most often cited reason is uninspiring or unsuitable pedagogical practices (Graham, Frederick, Byars-Winston, Hunter, \& Handelsman, 2013; Seymour \& Hewitt, 1997). Students' perceptions of teaching approaches and having agency in their own learning predict positive academic outcomes as well as satisfaction and skill development (Lizzio, Wilson, \& Simons, 2002). Thus, more engaging teaching practices are needed, followed by demonstrated success in providing supportive experiences for students from diverse backgrounds that increase confidence in applied skills and foster positive attitudes toward future learning.

In previous publications, we described the development of a multidisciplinary, project-based introductory statistics course ( $\mathrm{Di}$ erker, et al., 2012) aimed at engaging students in applied statistical projects across both divisional and departmental boundaries, as well as its success in attracting higher rates of URM students than a traditional introductory statistics curriculum offered through a math department (Dierker, et al., 2015). Funded by the National Science Foundation and first introduced into the curriculum at a selective liberal arts college, the project-based course engages students with real data and code-based statistical software. Closely following the recommendations outlined in the Guidelines for Assessment and Instruction in Statistics Education (GAISE) report (Aliaga et al., 2005), the course is designed around student research projects of their own choosing and offers individualized hands-on experience in applied statistics. Projects are presented at the end of the semester at a research poster session in which students have the opportunity to describe their process of inquiry, including the different decisions made along the way, their premises, conclusions and any barriers that they faced.

Rather than focusing on rules associated with traditional lists of statistical tools (e.g., z-test, one sample t-test, two sample t-test, paired t-test, etc.), we have organized the course according to the decisions and skills involved in statistical inquiry. Basic themes such as measurement and descriptive and graphical representation are 
covered, as well as more specific inferential methods needed to test hypotheses and/or explore the empirical structure of data (ASA, 20I4). All, however, are introduced as the student's research questions dictate their presentation. In this way, students are provided with opportunities to learn to evaluate what tools would be most appropriate for their research question(s) and to engage in decision making. While not all students utilize the entire menu of tools offered in this course, through on-line materials, in and out of class support and collaboration with peers, they are exposed to a wide variety of methods, and learn to choose and use them flexibly as they are needed. This approach is aimed at building student confidence in their ability to evaluate data and seek out appropriate methods for the questions at hand.

Importantly, the project-based course is aimed at taking advantage of students' natural curiosity and providing a common language for approaching questions across numerous disciplines. This is achieved by asking students in the first week of class to develop their own research question from a number of large data sets representing different disciplines such as ecology, psychology, economics, planetary science and more. Thinking with data to answer a research question is an important component of the course as is the connection to the applied content (ASA, 20I4). In addition, great care is taken to present translations of terminology and vocabulary that are used across different disciplines for similar statistical concepts (e.g. independent and dependent variables vs. predictors and outcomes vs. stimulus and response variables).

Based on survey and administrative data from students enrolling in the project-based course across 4 academic years, the present paper compares background characteristics, learning experiences and course outcomes for URM and non-URM students. The unique nature of the multi-disciplinary project-based course and its potential opportunity to contribute to increased retention in STEM makes consideration of the background, experiences, and outcomes of URM and non-URM students particularly important. Course experiences included measures such as the usefulness of resources and difficulty ratings, while measures of course outcomes focused on increases in confidence, knowledge level, and students' interest levels in conducting research, using statistics, and taking follow-up courses. We hypothesize that despite potential differences in background characteristics of these two groups, experiences with the course and course outcomes will be similarly positive. We used multivariate regression analyses to address whether differences related to URM status were present after controlling for students' other background characteristics and course experiences in order to have a fuller understanding of how the course engaged URM and non-URM students.

\section{METHODS}

\section{Participants}

Data were drawn from administrative records and student surveys completed before and after the multidisciplinary, project-based course $(N=333)$ between fall semester 2010 and fall semester 20I3. The pre course survey was completed prior to the end of the first week of classes and the post course survey during the last week of the semester. Each survey took approximately 10 - I 5 minutes to complete. The sample included $74(22.2 \%)$ students who self-reported as under-represented (i.e. African American and/or Hispanic). The remaining 259 students (77.8\%) self-reported as
White, Asian or other and were designated for the purposes of the present analyses as non-underrepresented. A total of 202 students $(61.0 \%)$ were female, and 140 (42.0\%) were in their first or second year of college.

The multidisciplinary, project-based introductory statistics course was offered through the Quantitative Analysis Center, a collaborative effort of academic and administrative departments that supports quantitative analysis across the curriculum and provides an institutional framework for collaboration across departments and disciplines in the area of statistics and data analysis. Titled Applied Data Analysis, the course was described in the university's on-line catalogue as a "project-based course, [in which] you will have the opportunity to answer questions that you feel passionately about through independent research based on existing data. Students will have the opportunity to develop skills in generating testable hypotheses, conducting a literature review, preparing data for analysis, conducting descriptive and inferential statistical analyses, and presenting research findings. The course offers unlimited one-on-one support, ample opportunities to work with other students, and training in the skills required to complete a project of your own design. These skills will prepare you to work in many different research labs across the University that collect empirical data. It is also an opportunity to fulfill an important requirement in several different majors." The course was open to all students and there were no prerequisites for enrollment. It represented one option to fulfill a major requirement for biology, earth and environmental science, government, neuroscience and behavior, sociology, and psychology or could be applied to the natural sciences and mathematics general education recommendation. The course was not specifically required of any student and did not represent the only option for fulfilling requirements for any major within the university. The average enrollment per class section was 17.8 (s.d. = 4.8 , range $=6-26$ ).

This project-based course differs from standard introductory statistics courses in several ways. Where traditional statistics courses often employ a building-block approach which covers statistical tools in a serial manner and in the absence of a context in which to apply them, this course entails learning statistics as students answer their own questions and choosing among statistical tools presented in a parallel manner. The course works to promote learning by creating a context in which students familiarize themselves with several possible data sets, formulate a statistical research question, choose among several available statistical tools, apply an appropriate method, and communicate their findings. Based on the student's choice of data, each generates testable hypotheses for their chosen dataset; conducts a literature review on their topic of interest; works to refine or broaden their research questions based on information they collect; prepares data for analysis (i.e., data management); selects and conducts descriptive and inferential statistical analyses; and evaluates, interprets and presents research findings. These activities are not presented or experienced as distinct stages but rather, as a series of ongoing, interactive tasks.

Learning materials and teaching strategies were designed to be structured enough to allow students to consistently move forward with their research projects, yet broad enough to encourage them to creatively and independently explore their questions, letting students actively drive the decisions involved in inquiry. In this way, the support each student receives is dictated by their own research 
question and the results at each stage of their project.

The semester-long course met 3 to 4 times a week for a total of 4 hours. On-line lecture clips were used to support a flipped classroom approach (e.g., Abeysekera \& Dawson, 2014) and were designed to provide students with adequate substantive and practical background for engaging in workshop-oriented class sessions and completing exams and cumulative project-based assignments toward the completion of their research project. During class sessions instructors and peer mentors supported students in making progress on their research project. Additional individualized support from statistical tutors was available during drop-in hours throughout the semester.

\section{Measures}

Measures included gender and the following variables:

Background Characteristics. Class year was dichotomized into Ist and 2nd year vs. upper classmen. Students' high school backgrounds were collapsed based on whether they attended a public vs. non-public high school. The non-public category included private schools, religious schools, and home-schools. Financial aid status was characterized as students with demonstrated need receiving grants and/or self-help financial aid vs. those enrolled in the university without financial assistance.

Students were asked to indicate on the pre course survey whether they had taken an Advanced Placement (AP) statistics course during high school and perceived skills in mathematics were measured by the questions. "How well did you do in mathematics courses you have taken in the past?" and "How good at mathematics are you?" both rated on a scale from I (very poor) to 7 (very well/good). Math SAT scores were drawn from administrative data.

Prior experience with programming and/or code-based statistical software was evaluated in the pre course survey. Individual programs endorsed by 4 or more students include Java, Python, Cl C++, Matlab, R, SAS, Stata, and SPSS.

Students were asked "How likely is it that you would have taken any course in statistics if such a course were not required". Response options ranged from I = not at all likely to 7 = very likely.

Experiences with the course. Based on the post course survey, students rated the usefulness of the flipped classroom sessions in completing both the research project and course exams on a scale from I = not at all useful to $5=$ extremely useful. Usefulness of course resources including readings, video lectures and model statistical code was also rated on a scale from I = not at all useful to 5 = extremely useful and averaged across individual responses related to both usefulness in terms of completing the research project and the exams.

Instructors, peer mentors, and tutors were also available outside of class sessions to provide additional one-on-one support. Students were asked to report the number of times they met with each and, if they used any support, were asked to rate how helpful this support was to them.Variables were dichotomized into whether or not a student visited each (i.e., instructors, peer mentors and tutors) and the helpfulness of each was rated on a scale from $\mathrm{I}=$ not at all helpful to $9=$ very helpful.

Students' perceptions of course rigor were measured with the questions "How difficult for you was the material covered in this course?" (from I = very easy to 7 = very difficult), "Was this course more challenging, less challenging or similarly challenging compared to other college courses you have taken?" and "How challenging was the research project?" from I = not at all challenging to $5=$ the most challenging project the student had ever completed.

Students' overall impressions of the course were measured with the questions "Did you accomplish more than you expected, less than you expected or about the same as you expected?" and "Did you find this course more useful, less useful or similarly useful compared to other college courses you have taken?"

Course outcomes. Increases in perceived confidence in several data analysis and statistical skills were evaluated based on student ratings from the pre to post course survey. These skills were evaluated with the questions how confident are you in examining codebooks, developing research questions, managing data, conducting research, conducting statistical analyses, graphing, interpreting results, effectively presenting statistical results, and understanding the discipline of statistics, each rated on a scale from I = not at all confident to $4=$ very confident. For students not rating themselves at the maximum confidence level in the pre-survey (leaving $72.2 \%-$ $98.6 \%$ of the sample) individual dichotomous variables were created for each skill indicating whether or not the student's confidence increased between the pre and post course surveys.

Knowledge of data analysis and statistical concepts was evaluated through 3 multiple-choice, in-class exams.

Students' interest in conducting research and using statistics was measured in both the pre survey and the post survey by two questions. "Are you interested in conducting research?" (from I $=$ not at all interested to $4=$ very interested) and "In the field in which you hope to be employed when you finish school, how much will you use statistics?" (from I = not at all to 7 = great deal). For students not rating themselves at the maximum interest level in the pre survey $(64.7 \%$ of the sample on research interest and $90.2 \%$ of the sample on statistics use in employment), dichotomous variables were created for each question indicating whether or not the students' interest increased between the pre and post surveys.

Finally, students were asked if they would like to take one or more courses as a follow-up to the project-based statistics course. Options included a course in programming, data set construction, data visualization, science writing, advanced statistics or other. Individual courses were examined separately and an aggregate variable was constructed indicating whether or not a student endorsed an interest in taking at least one follow-up course.

\section{Analyses}

Chi-square Tests of Independence and ANOVA were used to examine the association between URM status and categorical and continuous variables measuring student's background characteristics, experience with the course and course outcomes. Multivariate linear or logistic regression models, for continuous and binary outcome variables respectively, were then run to evaluate whether effects of URM status persisted when controlling for other significant background characteristics and course experiences.

\section{RESULTS \\ Background Characteristics}

Sixty-one percent of students enrolling in the course were female, $56.8 \%$ had attended a public high school and $22.5 \%$ reported having taken AP statistics during high school. Forty-two percent of the sample enrolled in the project-based course during their first or 
second year of college (i.e., freshman or sophomore class status), and half were receiving financial aid. The average Math SAT score was 689 (s.d. 70.4, range 500 to 800) and the mean rating on the questions "How well did you do in mathematics courses you have taken in the past?" and "How good at mathematics are you?" was 4.6 (s.d. I.44) and 4.8 (s.d. I.23), respectively, both rated on a scale from I =very poor to 7 =very well/good. The mean rating on the question "How likely is it that you would have taken any course in statistics if such a course were not required" was 4.4 (s.d. I.77) rated on a scale from I = not at all likely to $7=$ very likely. $31.1 \%$ of students reported at least some prior experience with a programming language or code-based statistical software.

A comparison of these background characteristics for under-represented (URM) and non-underrepresented students enrolling in the multidisciplinary, project-based course is presented in Table I. URM and non-URM students were similarly likely to be female, have attended a public high school, and to have taken an AP statistics course. URM and non-URM students were also similarly likely to enroll in the multidisciplinary project-based course during their first two years of college and to report having had some experience with at least one programming language or code-based statistical software. However, URM students were more than twice as likely as non-URM students to be receiving financial aid. Further, URM students enrolling in the project-based course had significantly lower math SAT scores than non-URM students and rated themselves as less good at math (Table I). URM students also reported that they would have been less likely than non-URM students to take a course in statistics if it were not required.

\section{Student Experiences with the Course}

Based on post survey responses, a comparison of self-reported experiences with the course by underrepresented student status is presented in Table 2. URM and non-URM students reported that the flipped classroom sessions (sample $M=3.6$, s.d. $=0.97$ ) and supporting course resources (sample $M=3.3$, s.d. $=0.79$ ) were similarly useful on a scale from I = not at all useful to $5=$ extremely useful. Further, both groups were similarly likely to take advantage of out-of class support by visiting instructors (sample rate $63.8 \%$ ), peer mentors (sample rate 60.3\%) and statistics tutors (sample rate $51.2 \%$ ) at least once and rated the support that they received in these sessions as similarly useful.While URM and non-URM students rated the research project as similarly challenging (sample $M$ $=2.7$, s.d. $=0.78$ on a scale from $\mathrm{I}=$ not at all challenging to $5=$ the most challenging project the student had ever completed), URM students described the material covered in the course as more difficult than non-URM students and were also more likely to rate the overall course as more challenging than other college courses they had taken (Table 2).

While URM and non-URM students were just as likely to rate the course as more useful than others they had taken in college (overall 50.8\%), URM students were significantly more likely to feel that they had accomplished more relative to what they had expected (Table 2).

\section{Course Outcomes: Knowledge, Confidence, Attitudes, and Future Plans Following the Course}

A comparison of course outcomes by underrepresented student

\section{TABLE I. Background characteristics of students enrolled in the multidisciplinary project-based course by underrepresented} student (URM) status.

\begin{tabular}{|c|c|c|c|}
\hline & $\begin{array}{l}\text { URM' } \\
n=74\end{array}$ & $\begin{array}{c}\text { non-URM } \\
n=259\end{array}$ & Statistics \\
\hline & $\mathrm{n}(\%)^{2}$ & $n(\%)$ & \\
\hline Ist or 2 nd year student & $36(48.6 \%)$ & $104(40.2 \%)$ & ns \\
\hline Public High School & 38 (5।.4\%) & I5I (58.3\%) & ns \\
\hline Programming Experience & $24(32.4 \%)$ & $80(30.9 \%)$ & ns \\
\hline Java & 8 (II.1\%) & $26(10.2 \%)$ & \\
\hline Python & $2(2.8 \%)$ & $17(6.7 \%)$ & \\
\hline $\mathrm{C} / \mathrm{C}++$ & 0 & $6(2.3 \%)$ & \\
\hline Stata & $5(6.9 \%)$ & $16(6.3 \%)$ & \\
\hline \multirow[t]{2}{*}{ SPSS } & $7(9.7 \%)$ & $19(7.4 \%)$ & \\
\hline & Mean (s.d.) & Mean (s.d.) & \\
\hline Math SAT & $621(77.2)$ & $709(53.6)$ & $F(I, 274)=107, p<.00 I$ \\
\hline How good at mathematics are you? $(I=$ very poor to $7=$ very good $)$ & $4.5(1.12)$ & $4.9(1.25)$ & $F(I, 323)=4.04, p<.05$ \\
\hline $\begin{array}{l}\text { How likely you would take a course in statistics if not required ( } I=\text { not } \\
\text { at all likely to } 7=\text { very likely) }\end{array}$ & $3.9(1.88)$ & $4.6(I .7 I)$ & $F(I, 325)=7.96, p<.01$ \\
\hline
\end{tabular}

Under-represented students includes those self-identifying as Black or Hispanic.

${ }^{2}$ Percentages are based on the number of respondents completing each item. 


\begin{tabular}{|c|c|c|c|}
\hline & $\begin{array}{l}\text { URM' } \\
n=74\end{array}$ & $\begin{array}{l}\text { non-URM } \\
n=259\end{array}$ & Statistics \\
\hline $\begin{array}{l}\text { Usefulness of flipped class sessions } M \text { (s.d.) } \\
(I=\text { not at all useful to } 5=\text { extremely useful) }\end{array}$ & $3.7(0.93)$ & $3.5(0.99)$ & ns \\
\hline $\begin{array}{l}\text { Usefulness of course resources }{ }^{2} M \text { (s.d.) } \\
(I=\text { not at all useful to } 5=\text { extremely useful })^{\text {a }}\end{array}$ & $3.3(0.7 I)$ & $3.3(0.8 \mathrm{I})$ & ns \\
\hline \multicolumn{4}{|l|}{ Out of class support } \\
\hline Visited instructor $\mathrm{n}(\%)^{3}$ & $50(67.6 \%)$ & $160(62.7 \%)$ & ns \\
\hline $\begin{array}{l}\text { Helpfulness of support } M \text { (s.d.) } \\
(I=\text { not at all helpful to } 9=\text { very helpful })\end{array}$ & $8.1(1.49)$ & $7.8(1.75)$ & ns \\
\hline Visited peer mentor $\mathrm{n}(\%)$ & $40(54.8 \%)$ & $126(50.2 \%)$ & ns \\
\hline $\begin{array}{l}\text { Helpfulness of support } M \text { (s.d.) } \\
(I=\text { not at all helpful to } 9=\text { very helpful })\end{array}$ & $7.6(2.01)$ & $7.2(1.67)$ & ns \\
\hline Visited statistics tutor $\mathrm{n}(\%)$ & $50(69.4 \%)$ & $146(57.7 \%)$ & ns \\
\hline $\begin{array}{l}\text { Helpfulness of support } M(\text { s.d. }) \\
(I=\text { not at all helpful to } 9=\text { very helpful })\end{array}$ & $7.5(2.13)$ & $6.9(2.25)$ & ns \\
\hline \multicolumn{4}{|l|}{ Rigor } \\
\hline $\begin{array}{l}\text { How difficult for you was the material covered in this course? } M \text { (s.d.) } \\
(I=\text { not at all difficult to } 7=\text { very difficult })\end{array}$ & $4.3(1.25)$ & $3.9(1.36)$ & $F(I, 329)=6.01, P=.015$ \\
\hline More challenging compared to others college courses $\mathrm{n}(\%)$ & $23(31.9 \%)$ & $28(11.0 \%)$ & $X^{2}(I)=17.2, p<.001$ \\
\hline $\begin{array}{l}\text { How challenging was the research project? } M(\text { s.d. }) \\
(I=\text { not at all to } 5=\text { the most challenging })\end{array}$ & $2.8(0.74)$ & $2.7(0.78)$ & ns \\
\hline Overall & $\mathrm{n}(\%)$ & $\mathrm{n}(\%)$ & \\
\hline Accomplished more relative to what you expected & $38(53.5 \%)$ & $86(33.7 \%)$ & $X^{2}(I)=8.4, p<.004$ \\
\hline More useful than other college courses & $32(44.4 \%)$ & $134(52.5 \%)$ & ns \\
\hline
\end{tabular}

'Under-represented students includes those self-identifying as Black or Hispanic.

${ }^{2}$ Averaged across individual items of readings, lectures, and sample statistical code.

${ }^{3}$ Percentages are based on the number of respondents completing the particular item.

status are presented in Table 3. Based on responses in both the pre and post course surveys, URM and non-URM students reported increased confidence following the course at similar rates for each of the skills covered (i.e. overall increases for examining codebooks $81.2 \%$, developing research questions $68.0 \%$, managing data $60.9 \%$, conducting research $46.9 \%$, conducting statistical analyses $65.8 \%$, graphing $53.3 \%$, interpreting results $51.1 \%$, effectively presenting results $48.8 \%$, and understanding the discipline of statistics 59.2\%). While both URM and non-URM students performed well on exams measuring knowledge of statistical concepts, URM students received significantly lower scores than non-URM students on each of the three multiple choice exams administered during the course (Table 3).

Notably, URM students had reported lower levels of interest in conducting research than non-URM students in responses in the pre course survey $(M=2.9$, s.d. $=0.78$ vs. $M=3 . I$, s.d. $=0.8 \mathrm{I}), F(I, 323)$ $=4.2 \mathrm{I}, \mathrm{p}=.04)$, and were significantly more likely to report that their interest in conducting research had increased following the course (Table 3). Approximately $40 \%$ of both URM and non-URM students showed increases in how much they believe that they will use statistics in the field in which they hope to be employed.

Finally, more than $80 \%$ of students enrolling in the project-based course reported being interested in one or more follow-up courses including computer programming, constructing data sets, data visualization, science writing and advanced statistics. Though URM and non-URM students endorsed the majority of these courses at similar rates, URM students were significantly less likely than non-URM students to be interested in taking a computer programming course following the project-based course (Table 3).

\section{Multivariate Analyses Examining Predictors of Course Outcomes}

Multivariate regression models were built by first entering background characteristics based on the pre course survey and administrative data into each multivariate model. Only those variables that reached statistical significance were retained in subsequent models. Next, items from the post survey assessing students' experience with the course were simultaneously entered into models for each outcome on which there were significant differences related to URM status.

While the bivariate analyses demonstrated differences based on URM status for several background characteristics, learning experiences, and course outcomes, URM status did not significantly predict any of the course outcomes with the exception of increase in interest in conducting research when controlling for the other predictors. That is, after controlling for pre course interest in research, other significant background characteristics and all measures of experiences with the course, URM students were found to be 2.2 times $(\mathrm{Cl}$ I.I4.6) more likely to report that their interest in conducting research had increased following the course. In addition, higher ratings on the usefulness of course resources $(O R=1.6 \mathrm{Cl} I .0 \mathrm{I}-2.56)$, lower ratings of the challenge involved in the research project $(O R=0.6 \mathrm{Cl} 0.38$ 0.97 ) and reporting that the course was more useful than others tak- 
TABLE 3. Achievement, confidence, attitudes and future plans following the multidisciplinary project-based course by underrepresented student (URM) status.

\begin{tabular}{|c|c|c|c|}
\hline & $\begin{array}{l}\text { URM' } \\
n=74\end{array}$ & $\begin{array}{c}\text { non-URM } \\
n=259\end{array}$ & Statistics \\
\hline Increased confidence pre to post & $n(\%)^{2}$ & $\mathrm{n}(\%)^{2}$ & \\
\hline Examining data codebooks & $56(77.8 \%)$ & $203(82.2 \%)$ & ns \\
\hline Developing a research question & $4 \mid(67.2 \%)$ & 146 (68.2\%) & ns \\
\hline Managing data & $43(62.3 \%)$ & 147 (60.5\%) & ns \\
\hline Conducting research & $28(44.4 \%)$ & I0I (47.6\%) & ns \\
\hline Conducting statistical analyses & $44(62.0 \%)$ & $164(66.9 \%)$ & ns \\
\hline Graphing & $33(48.5 \%)$ & $130(54.6 \%)$ & ns \\
\hline Interpreting results & $31(44.9 \%)$ & $128(52.9 \%)$ & ns \\
\hline Effectively presenting results & $25(54.3 \%)$ & $73(47.1 \%)$ & ns \\
\hline Understanding the discipline of statistics & $4 \mathrm{I}(57.5 \%)$ & $142(59.7 \%)$ & ns \\
\hline Exam I M correct (s.d.) & $86.9 \%^{3}(7.8)$ & $91.5 \%(5.9)$ & $F(I, 304)=28.5, p<.0 I$ \\
\hline Exam 2 M correct (s.d.) & $83.7 \%(12.6)$ & $90.3 \%(7.7)$ & $F(I, 30 I)=28.5, p<.0 I$ \\
\hline Exam $3 M$ correct (s.d.) & $85.6 \%(9.0)$ & $90.0 \%(6.7)$ & $F(I, 299)=|8.8, p<.0|$ \\
\hline Attitudes pre to post & $\mathrm{n}(\%)^{2}$ & $\mathrm{n}(\%)^{2}$ & \\
\hline Increased interest in conducting research & $22(42.3 \%)$ & $46(29.1 \%)$ & $X^{2}(I)=5.17, p=.02$ \\
\hline \multirow[t]{2}{*}{ Increased expectation of using statistics in future employment } & $29(43.9 \%)$ & $87(38.5 \%)$ & ns \\
\hline & n (\%) & $\mathrm{n}(\%)$ & \\
\hline Interest in taking a follow-up course & $56(76.7 \%)$ & $216(83.7 \%)$ & ns \\
\hline Programming & $18(24.7 \%)$ & $107(41.5 \%)$ & ns \\
\hline Data set construction & $21(28.8 \%)$ & $78(30.2 \%)$ & ns \\
\hline Data visualization & $22(30.1 \%)$ & $90(34.9 \%)$ & ns \\
\hline Science Writing & $13(17.8 \%)$ & $57(22.1 \%)$ & ns \\
\hline Advanced Statistics & $24(32.9 \%)$ & II 3 (43.8\%) & ns \\
\hline Other & $8(10.8 \%)$ & $16(6.2 \%)$ & ns \\
\hline
\end{tabular}

'Under-represented students includes those self-identifying as Black or Hispanic.

${ }^{2} \mathrm{n}$ and $\%$ based on number of students who were able to increase their confidence rating between the pre and posttest (i.e. those not rating themselves at the maximum confidence level in the pretest.

${ }^{3}$ Percentages are based on the number of respondents completing each item. Bonferoni adjusted $\mathrm{p}$ values are presented to correct for multiple tests when there are sets of items (increased confidence, exam scores, follow-up courses).

en in college ( $\mathrm{OR}=2.6 \mathrm{Cl}$ I.32-5.30) also independently predicted the likelihood of increased student interest in conducting research.

When examining the association between students' background characteristics and average exam scores (the other course outcome on which URM and non-URM students had differed in the bivariate analyses) non-URM student status, higher Math SAT scores, and junior or senior class status each independently predicted a higher average score on multiple choice exams. However, when entering measures of student experiences with the course into the model, URM status was no longer associated with performance on exams, though Math SAT (Beta .0004, $\mathrm{p}<.000 \mathrm{I}$ ) and class status remained significant (Beta 0.02, $\mathrm{p}<.04$ ). In addition, higher ratings on the usefulness of flipped classroom sessions (Beta 0.0I, $p<.009$ ), lower ratings on having accomplished more than expected (Beta $-0.02, p<.03$ ) and reports that the course was more useful than others taken in college (Beta $0.02, p<.004$ ) were also found to independently predict higher exam scores.

\section{DISCUSSION}

We have described in previous reports the development of this project-based, introductory statistics course and its success in at- tracting higher rates of URM students compared to a traditional statistics curriculum offered by a math department (Dierker et al., 2012; Dierker et al., 2015). Based on survey and administrative data from students enrolling in the project-based course across 4 years, the present study compared URM and non-URM students on background characteristics, learning experiences and course outcomes to evaluate the success of the course in increasing confidence in applied skills and fostering positive attitudes toward future learning for students from diverse backgrounds.

Results indicated that URM students entered the course with lower levels of confidence in their math skills, lower Math SAT scores and a lower likelihood of taking a statistics course if one were not required than non-URM students. While URM students also rated the course as more difficult than non-URM students, the URM students were more likely to report accomplishing more than expected. URM students scored somewhat lower on multiple choice exams evaluating content knowledge outcomes; however this was no longer significant after controlling for other background characteristics and course experiences. Both URM and non-URM students showed similarly high rates of increased confidence and interest in pursuing follow-up courses. Furthermore, after controlling for pre course 
interest in research, student background characteristics and experiences with the course, URM students were found to be over 2 times more likely than non-URM students to report that their interest in conducting research had increased. Overall, half of the students in the sample reported the course to be more useful than other college courses they had taken and more than three-quarters of the sample reported interest in taking at least one follow-up course, with no differences based on URM status.

Despite URM students rating themselves more poorly in terms of math skills and scoring somewhat lower than non-URM students on the math section of the SAT, it should be noted that because of the selective nature of the university in which this project-based course was piloted, SAT scores for both groups are quite high, with both mean and median scores above 600. In other words, scores for the URM students in this study were not low, but instead, relatively lower than those of non-URM students enrolling in the course. Notably, previous research has shown that African American and Hispanic college students with high grade point averages and SAT scores above 600 typically do not pursue STEM college majors for reasons including poor teaching in STEM courses, lack of encouragement from teachers or parents, and self-perception of their own inability to be successful in STEM majors (George, Neale,Van Horne, \& Malcolm 200 I; Grandy, 1998). Thus, this is a particularly important group to target with an innovative, welcoming curriculum that sparks interest in continued study. Given that more than three-quarters of URM students in the present study reported being interested in one or more follow-up courses and there were no URM-based differences in increased confidence in particular research and statistical skills, our project-based approach seems to have been a largely positive experience for these students, consistent with the literature showing increased motivation and more positive attitudes towards a discipline when taught via a project-based approach (Walker \& Leary, 2009). While we are not yet able to evaluate the potential impact of the project-based course in terms of actual future academic decisions-making, the present findings suggest that a course in which students "have the opportunity to answer questions that [they] feel passionately about through independent research based on existing data", may represent a promising option for engaging diverse students in the process of statistical inquiry.

Overall though, only $42 \%$ of students enrolling in the project-based course did so during their first two years of college. Given that participation by freshman and sophomores in introductory statistics courses has the best chance of influencing students' selection of both future courses as well as a major discipline, by extension, it also has the most hope for reversing the 'leaky pipeline' in which large numbers of students turn away from STEM courses (Blickenstaff, 2005).More needs to be done to encourage enrollment of students in statistics courses as early as possible in their academic careers (Seymour, Hunter, Laursen, \& Deantoni, 2004; ASA, 20 I4; Hurtado et al., 2008).

Though some differences were found between URM and nonURM students' experiences with the course including URM students rating the course material as more difficult and being more likely to view the course as more challenging than others they had taken in college, those experiences as well as significant differences in background characteristics between URM and non-URM students did not significantly predict course outcomes in multivariate models. Instead, ratings of the usefulness of flipped classroom sessions and supporting course resources and judging the course to be more useful than other college courses (measures on which the URM and non-URM students did not differ) were the most consistent predictors of positive course outcomes. One or more of these measures independently predicted higher exam scores and an increased interest in conducting research.

Notably, while bivariate analyses showed that URM students were found to be more likely to feel that they accomplished more than expected in the course, it was lower ratings of accomplishing more than expected that was found to predict higher exam scores. This coupled with a positive association between both Math SAT scores and higher class status (i.e. junior and senior) in accounting for significant variability in exam scores suggests that test scores were potentially driven by experience and confidence in taking traditional tests.

Taken together, we see that it is important to examine additional experience and outcome measures, beyond the typical content knowledge exams. This is especially relevant as the most beneficial effects of project-based learning are on measures that consider the application, as opposed to the memorization, of knowledge (Dochy, Segers, Van den Bossche, \& Gijbels, 2003) and it is potentially these additional application outcomes and attitudes that are most important to continued persistence in statistics. Given that no single course will adequately prepare students for either the amount or complexity of data they will encounter as professionals and as citizens (Resnick, 1987; Collins \& Halverson, 2010), modern courses need to focus on imparting a deep interest among students, belief in the importance of the discipline and a desire to continue learning statistics and disciplines focused on data and computation.

Though URM status was not found to be independently associated with the vast majority of course outcomes, after controlling for pre course rating of interest in research, significant background characteristics and students' experiences with the course, URM students were found to be more than two times more likely than non-URM students to report that their interest in conducting research had increased. Students' increased interest in research is critical since early participation in research has been shown to be an important factor in retaining students in STEM (Hunter, Laursen, \& Seymour, 2007; Pascarella \& Terenzini, 2005) given that it increases skills and a sense of identity as a researcher (Graham et al., 2013; Hurtado, Cabrera, Lin, Arellano, \& Espinosa, 2009). The applied focus of this project-based course adds to a literature already showing that research experience in courses (e.g., Hatfull et al., 2006; Schaffer et al., 20l4) can provide benefits similar to those achieved through independent research in a faculty lab (Linn, Palmer, Baranger, Gerard, \& Stone, 2015; Lopatto, 2007; Seymour et al., 2004).

Though we believe that this inclusive and comparative approach allows students to widely communicate across disciplines on a variety of computational issues, we also recognize that there is more to be done to enhance access to truly interdisciplinary research and thinking. Project-based learning, of course, presents its own challenges and customarily, courses offering opportunities for independent statistical inquiry have required a smaller group format (e.g. 20 or fewer students) compared to courses that rely on more traditional pedagogies. As noted in the methods, during development of our project-based course, the average class sections did not go above 26. More recent offerings of the project-based course have increased most sections sizes to 30 students (fall 20I4) with great success, and with fall 2015 , we have moved out of the computer lab into collaborative space that will allow students the mobility of laptops, the flexibility of differ- 
ent table and seat configurations and space for sections of 50 to 60 students. With the appropriate supporting infrastructure (e.g. helpful materials for outside of class that enhance engagement in active class sessions and a network of peer mentors), we hope to demonstrate that this project-based approach can be delivered by expending no more resources than many traditional lecture courses.

Previous research has recognized the general challenge in teaching courses in statistics at both the undergraduate and graduate level. There is no typical statistics student; instead, students come into statistics courses with differing backgrounds, experiences, learning styles and levels of preparation. This project-based course provokes students to encounter (and struggle with) the central concepts and principles not only within the discipline of statistics, but also with the discipline that their chosen research reflects. Although our model focuses on statistics education, the emphasis on authentic real-world activities with the goal of sparking interest and enthusiasm (BIE, 20I2) can be achieved in curricular content as diverse as science (Kubiatko \& Vaculová, 20II) and foreign language (Danan, 20l0) instruction. In addition to the specific skills most directly emphasized, project-based courses provide students with experience in communication, organization and time management (BIE, 20I2). We believe that our course can benefit other universities not only through dissemination of our model and experiences, but by making our newly developed resources widely available. We are happy to share our course materials with others and encourage faculty to consider integrating project-based course content (http://passiondrivenstatistics.com).

\section{REFERENCES}

Abeysekera, L., \& Dawson, P. (20I4). Motivation and cognitive load in the flipped classroom: definition, rationale and a call for research. Higher Education Research \& Development, (May 20 I5), 37-4I. doi :10.1080/07294360.2014.934336

Aliaga, M., Cuff, C., Garfield, J., Lock, R., Utts, J., \& Witmer, J. (2005), Guidelines for Assessment and Instruction in Statistics Education (GAISE): College Report. American Statistical Association. Available at: http://www.amstat.org/education/gaise/

Aditomo,A., Goodyear, P., Bliuc,A. M., \& Ellis, R.A. (20I3). Inquiry-based learning in higher education: principal forms, educational objectives, and disciplinary variations. Studies in Higher Education, 38(9), 1239-1258.

American Statistical Association [ASA]. (20I4), Curriculum guidelines for undergraduate programs in statistical science. http://www. amstat.org/education/curriculumguidelines.cfm

Bailey, B., Spence, D. J., \& Sinn, R. (2013). Implementation of Discovery Projects in Statistics. Journal of Statistics Education, 2 I (3), I-24.

Buck Institute for Education (BIE) and Boise State University, Department of Educational Technology; http://pbl-online.org/ accessed April I, 2012.

Bilgin, A.A., Newbery, G., \& Petocz, P. (20I5). Engaging and motivating students with authentic statistical projects in a capstone unit. In M. A. Sorto (Ed.), Advances in Statitsics Education: Developments, Experiences, and Assessments. Proceedings of the Satellite Conference of the International Association for Statistics Education, Rio de Janiero, Brazil.

Blickenstaff, J. C. (2005). Women and science careers: Leaky pipeline or gender filter? Gender and Education, I7, 369-386, DOI: I0.1080/09540250500|45072

Collins, A., \& Halverson, R. (2010). The second educational revolution: rethinking education in the age of technology. Journal of computer https://doi.org/10.20429/ijsotl.2016.100102 assisted learning, 26(I), 18-27.

da Silva, M. M. P., \& Pinto, S. S. (20|4). Teaching statistics thorugh learning projects. Statistics Education Research Journal, 13, I77 - 186.

Danan, M. (20I0). Dubbing projects for the language learner: a framework for integrating audiovisual translation into task-based instruction. Computer assisted language learning, 23(5), 44 I-456.

Dierker L, Kaparakis E, Rose J, Selya A, Beveridge D.(2012) Strength in Numbers:A multidisciplinary, project-based approach to introductory statistics education. Journal of Effective Teaching. I 2(2):414.

Dierker, L., Cooper, J., Selya, A., Alexander, J., Rose, J. (20I5) Evaluating access:A comparison of demographic and disciplinary characteristics of students enrolled in a traditional introductory statistics course vs. a multidisciplinary, project-based course, Interdisciplinary Studies of Education. 4(I), 22-37

Dochy, F., Segers, M.,Van den Bossche, P., \& Gijbels, D. (2003). Effects of problem-based learning: A meta-analysis. Learning and instruction, 13(5), 533-568.

George,Y.S., Neale, D. S.,Van Horne,V., \& Malcolm, S. M. (200I). In pursuit of a diverse science, technology, engineering, and mathematics workforce. American Association for the Advancement of Science.

Graham, M. J., Frederick, J., Byars-Winston, A., Hunter, A. B., \& Handelsman, J. (20I3). Increasing Persistence of College Students in STEM. Science, 34 I (6I53), | 455- | 456.

Grandy, J. (1998). Persistence in science of high-ability minority students: Results of a longitudinal study. Journal of Higher Education, 589-620.

Harada,V. H., \& Yoshina, J. M. (2004). Moving from Rote to Inquiry: Creating Learning That Counts. Library Media Connection, 23(2), 22.

Hatfull, G. F., Pedulla, M. L., Jacobs-Sera, D., Cichon, P. M., Foley,A., Ford, M. E., ... \& Hendrix, R. W. (2006). Exploring the mycobacteriophage metaproteome: phage genomics as an educational platform. PLoS genetics, 2(6), e92.

Hickey, D. T., Kindfield, A. C., Horwitz, P., \& Christie, M. A. (1999). Advancing educational theory by enhancing practice in a technology-supported genetics learning environment. Journal of Education, 25-55.

Hickey, D. T., Wolfe, E.W., \& Kindfield, A. C. (2000). Assessing learning in a technology-supported genetics environment: Evidential and systemic validity issues. Educational Assessment, 6(3), I55-196.

Higher Education Research Institute [HERI] (20I0) http://www.heri.ucla.edu/publications-main.php

Hmelo-Silver, C. E., Duncan, R. G., \& Chinn, C. A. (2007). Scaffolding and Achievement in Problem-Based and Inquiry Learning: A Response to Kirschner, Sweller, and Clark (2006). Educational Psychologist, 42(2), 99-107. doi: I0.1080/0046 I52070I 263368

Hunter, A. B., Laursen, S. L., \& Seymour, E. (2007). Becoming a scientist: The role of undergraduate research in students' cognitive, personal, and professional development. Science Education, 9I (I), 36-74.

Hurtado, S., Eagan, M. K., Cabrera, N. L., Lin, M. H., Park, J., \& Lopez, M. (2008). Training future scientists: Predicting first-year minority student participation in health science research. Research in Higher Education, 49(2), I 26-| 52. doi: | 0. I007/s | | | 62-007-9068- I

Hurtado, S., Cabrera, N. L., Lin, M. H., Arellano, L., \& Espinosa, L. L. (2009). Diversifying science: Underrepresented student experiences in structured research programs. Research in Higher Education, 50(2), |89-2 |4. doi: | 0.1007/s | | |62-008-9| |4-7

Jones, B.F., Rasmussen, C., \& Moffitt, M. (1997). Real-Life Problem Solv- 
ing: A collaborative approach to interdisciplinary learning. (Psychology in the Classroom: A Series on Applied Educational Psychology). Washington DC:American Psychological Association.

Kirschner, P.A., Sweller, J., \& Clark, R. E. (2006). Why minimal guidance during instruction does not work: An analysis of the failure of constructivist, discovery, problem-based, experiential, and inquiry-based teaching. Educational psychologist, 4 I (2), 75-86.

Krajcik, J.S. \& Blumenfeld, P. (2006). Project-based learning. In Sawyer, R. K. (Ed.), The Cambridge handbook of the learning sciences (pp. 317-333). New York: Cambridge University Press.

Kubiatko, M., \& Vaculová, I. (20I I). Project-based learning: characteristic and the experiences with application in the science subjects. Energy Education Science and Technoogy - Social and Educational Studies 3, 65-74.

Langer, J.A. (200I). Beating the odds:Teaching middle and high school students to read and write well. American Educational Research Journal, 38, 837-880.

Linn, M. C., Palmer, E., Baranger, A., Gerard, E., \& Stone, E. (20I5). Undergraduate research experiences: Impacts and opportunities. Science, 347. doi: 10.1126/science.1261757

Lizzio, A., Wilson, K., \& Simons, R. (2002). University Students' Perceptions of the Learning Environment and Academic Outcomes: Implications for theory and practice. Studies in Higher Education, 27(I), 27-52. doi: I0.1080/03075070I20099359

Lopatto, D. (2007). Undergraduate Research Experiences Support Science. CBE Life Sciences Education, 6, 297-306. doi: I0. I I87/cbe.07

Lynch, S., Kuipers, J., Pyke, C., \& Szesze, M. (2005). Examining the effects of a highly rated science curriculum unit on diverse students: Results from a planning grant. Journal of Research in Science Teaching, 42(8), 912-946.

Mergendoller, J. R., Maxwell, N. L., \& Bellisimo, Y. (2006). The effectiveness of problem-based instruction: A comparative study of instructional methods and student characteristics. Interdisciplinary Journal of Problem-based Learning, I (2), 5.

Nathan, M. J., Rummel, N., \& Hay, K. E. (in prep). Growing the learning sciences: brand or big tent? implications for graduate education. Available at http://website.education.wisc.edu/ mnathan/Publications_files/In_Prep_NathanRummelHay_GrowingLearningSciences.pdf

Madlung, A., Bremer, M., Himelblau, E., \& Tullis, A. (20II). A Study Assessing the Potential of negative effects in interdisciplinary Math-Biology instruction. CBE Life Sciences Education, 10, 43-54. doi: 10.1 187/cbe.10-08-0102

National Science Foundation, National Center for Science and Engineering Statistics. 2004. Women, Minorities, and Persons with Disabilities in Science and Engineering: 2004.Arlington,VA.

Nolan, D., \& Temple Lang, D. (2009). Approaches to broadening the statistics curricula. In M. C. Shelley, L. D. Yore \& B. Hand (Eds.), Quality Research in Literacy and Science Education (pp. 357-38I). London, UK: Springer.

Pascarella, E.T., \& Terenzini, P.T. (2005). How college affects students: A third decade of research (Vol. 2). San Francisco: Jossey-Bass.

Resnick, L. B. (1987). The 1987 presidential address: Learning in school and out. Educational researcher, I3-54.

Russell, S. H., Hancock, M. P., \& McCullough, J. (2007). Benefits of undergraduate research experiences. Science, 3/6, 548-549. doi: I0.I | 26/science. I |40384

Shaffer, C. D., Alvarez, C. J., Bednarski, A. E., Dunbar, D., Goodman, A. L., Reinke, C., ... Elgin, S. C. R. (20I4). A Course-Based Research
Experience: How Benefits Change with Increased Investment in Instructional Time. CBE Life Sciences Education, I3(1), III-I30. doi: 10.1 187/cbe-13-08-0152

Schultz, P.W., Hernandez, P. R., Woodcock, A., Estrada, M., Chance, R. C., Aguilar, M., \& Serpe, R. T. (20II). Patching the Pipeline: Reducing Educational Disparities in the Sciences Through Minority Training Programs. Educational Evaluation and Policy Analysis, 33(I), 95-I |4. doi: I0.3 I02/0I623737I039237|

Seymour, E., \& Hewitt, N. M. (1997). Talking about leaving: Why undergraduates leave the sciences (Vol. 12). Boulder, CO:Westview Press.

Seymour, E., Hunter, A.-B., Laursen, S. L., \& Deantoni, T. (2004). Establishing the benefits of research experiences for undergraduates in the sciences: First findings from a three-year study. Science Education, 88(4), 493-534. doi: 10.1002/sce.10131

Taulbee Survey, Computing Research Association. (20I3). Taulbee survey. Retrieved March 20, 2015 from http://cra.org/uploads/documents/resources/crndocs/2013-Taulbee-Survey.pdf

Tishkovskaya, S., \& Lancaster, G. (20I2). Statistical education in the 2 Ist century: A review of challenges, teaching innovations and strategies for reform. Journal of Statistics Education, 20(2).

Walker, A., \& Leary, H. (2009). A Problem Based Learning Meta Analysis: Differences Across Problem Types, Implementation Types, Disciplines, and Assessment Levels. Interdisciplinary Journal of Problem-Based Learning, 3, 6-28. doi: 10.7771//541-5015.106 I

Warwick, P., \& Ottewill, R. (2004). How can "problem subjects" be made less of a problem? Teaching in Higher Education, 9(3), 337347. doi: I0.1080/|35625 I0420002 |665|

Whittaker, J.A., \& Montgomery, B. L. (20I2). Cultivating Diversity and Competency in STEM: Challenges and Remedies for Removing Virtual Barriers to Constructing Diverse Higher Education Communities of Success. Journal of Undergraduate Neuroscience Education, I I ( I), A44-A5I.

Wuchty, S., Jones, B. F., \& Uzzi, B. (2007). The increasing dominance of teams in production of knowledge. Science, 3/6(5827), I0361039. 